\title{
Thin-strut bioresorbable-polymer sirolimus-eluting stent use for an optimal result of rescue coronary angioplasty in acute myocardial infarction failed thrombolytic therapy: the Bangladesh National Heart Foundation Annual Conference OCT-assisted live case
}

\author{
Fazila-Tun-Nesa Malik ${ }^{1}$, Ashok Dutta ${ }^{1}$, Dhiman Banik ${ }^{1}$, Tawfiq Shahriar Huq ${ }^{1}$, Muhammad Kalimuddin ${ }^{1}$, \\ Filip Mikołajczyk², Piotr Musialek ${ }^{3}$
}

${ }^{1}$ Department of Cardiology, National Heart Foundation Hospital \& Research Institute, Dhaka, Bangladesh

${ }^{2} \mathrm{KCRI}$, Krakow, Poland

${ }^{3}$ Department of Cardiac and Vascular Diseases, Jagiellonian University, John Paul II Hospital, Krakow, Poland

Adv Interv Cardiol 2021; 17, 3 (65): 309-312

DOI: https://doi.org/10.5114/aic.2021.109834

A 47-year-old man, smoker, was transferred to the Department of Cardiology Catheterization Laboratory at the National Heart Foundation (NHF) Hospital \& Research Institute [1] in Dhaka, Bangladesh, from a remote hospital after streptokinase failure to reperfuse anterior ST-elevation acute myocardial infarction (STEMI).

The patient had presented in a local hospital with a severe retrosternal pain of 6-hour duration (transportation $>2 \mathrm{~h}$ ). A diagnosis of anterior STEMI was made. The patient received i.v. morphine (8 $\mathrm{mg}$ ) and intravenous streptokinase (STK, 1.5 million units i.v.) as the first-line reperfusion therapy in most areas of Bangladesh. Other medications were oral aspirin (300 mg), loading dose of generic clopidogrel (300 mg), and high-dose $(80 \mathrm{mg})$ generic atorvastatin, all of which are now manufactured in the country.

Due to on-going severe chest pain in absence of any reperfusion signs (such as reperfusion arrhythmia or ST segment resolution), $2.5 \mathrm{~h}$ after STK administration, ground transportation to Dhaka was arranged for endovascular rescue. The patient arrived at the NHF cathlab $16 \mathrm{~h}$ from the chest pain onset, during the annual NHF Hospital \& Research Institute Interventional Cardiology Conference. Admission ECG showed persistent ST segment elevation in the anterior leads; echocardiography demonstrated left ventricular (LV) anterior wall akinesia with normal muscle thickness and hypercontractility of the inferior segments (overall LV ejection fraction of 35\%) in absence of any significant valvular or other pathology. The patient consented to be treated as a live case transmitted to the main auditorium, with interactions from the panel and participants (physicians, cathlab nurses, and cardiac technicians).

Coronary angiography showed a proximal left anterior descending (LAD) coronary artery occlusion (Figure $1 \mathrm{~A}$ ). Unfractionated heparin was used for peri-procedural anticoagulation. After vessel wiring, thrombus aspiration was performed using Export 6F (Medtronic) aspiration catheter (Figure $1 \mathrm{~B}$, arrow, effectively removed red and white thrombi in the basket, inset). For educational purposes it was interactively discussed that technically suboptimal coronary thrombectomy, including incomplete/non-axial guiding catheter engagement, may cause, through a "drag-and-drop" effect, coronary and cerebral embolism and stroke $[2,3]$. However, it is methodologically incorrect to assign to thrombectomy strokes occurring $48 \mathrm{~h}$ to 6 months after thrombectomy-assissted primary percutaneous coronary intervention $(\mathrm{PCl}$ ) (note 37 late strokes in the thrombectomy arm vs. 23 late strokes in the $\mathrm{PCl}$ alone arm of, respectively, 5033 and 5030 patients in the TOTAL study [4]) making the study conclusion essentially flawed (for the TASTE study fundamental design flaw, including enrollment limited to patients who would not require or benefit from thrombectomy in the operator's opinion [5]). Because thrombus embolism aggravates myocardial injury $[2,3,6,7]$, aspiration thrombectomy should remain

Corresponding author:

Piotr Musialek MD, DPhil, Department of Cardiac and Vascular Diseases, Jagiellonian University, John Paul II Hospital, 80 Pradnicka St, 31-202 Krakow, Poland, phone: +48 12 6142287, fax: +48 12 6143334, e-mail: pmusialek@szpitaljp2.krakow.pl

Received: 29.09.2021, accepted: 5.10.2021. 

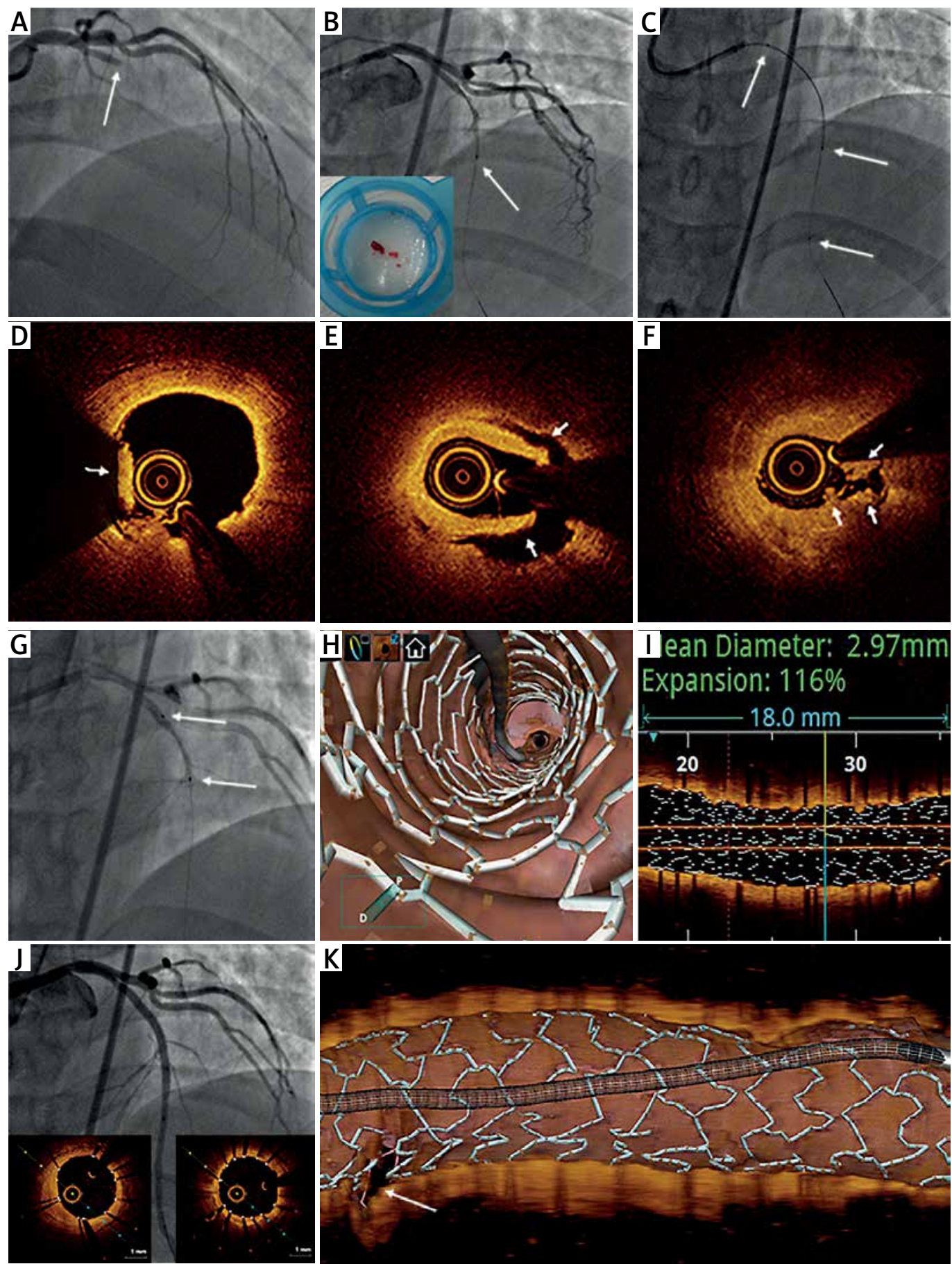

Figure 1. Angiography and optical coherence tomography imaging in a novel thin-strut bioresorbable-polymer sirolimus-eluting stent use in thrombus aspiration-assisted coronary angioplasty in acute myocardial infarction. A - proximal left anterior descending (LAD) occlusion (arrow). B - thrombus aspiration (second run, note contrast stagnation) using Export 6F (Medtronic) aspiration catheter (arrow); note white and red thrombi removed from the infarct-related artery, as shown in the aspiration system's basket (B, inset). C - OCT run (Ilumien Optis Imaging System, Abbott) visualized residual red thrombus (D), ruptured plaque (E), and white thrombus (F). A novel thin-strut bioresorbable-polymer sirolimus-eluting stent (G, Alex Plus $3.0 \times 18 \mathrm{~mm}$, Balton, Poland, arrows) was implanted directly with a single inflation at 10-12 atm (30 s) with an optimal angiographic result and lack of any distal embolism (J). OCT demonstrated an optimal reconstruction of the lumen in absence of any dissection and in absence of any in-stent thrombotic or plaque material ("fly-through" image in $\mathrm{H}$, the achieved vessel/stent diameter and stent expansion parameters in I, apposition in J (insets)) whereas 3D reconstruction (K) demonstrated a fully preserved side-branch access - another important feature of the stent design 
an essential consideration in primary angioplasty in acute myocardial infarction [5, 7-9], similar to the fundamental role played by thrombectomy in acute ischemic stroke interventions [10]. This should be paired with optimal stent use to achieve best outcomes in vessel lumen reconstruction and long-term clinical outcomes.

Thrombolysis in myocardial infarction residual thrombus grade [7] was 2 out of 5. After i.v. nitroglycerin administration, optical coherence tomography (OCT, llumien Optis Imaging System, Abbott) run was employed to understand [11] the residual thrombotic material and plaque (Figures 1 D-F). A novel thin-strut bioresorbable-polymer sirolimus-eluting stent (Alex Plus $3.0 \times 18 \mathrm{~mm}$, Balton, Poland) [12-15] was implanted (direct stenting, 10-12 atm/30 s). Control angiography (Figure $1 \mathrm{~J}$ ) showed lack of any residual stenosis and lack of distal embolism; there was TIMI-3 (TIMI Myocardial Perfusion Grade 2/3) [3]. OCT demonstrated an optimal reconstruction of the lumen in absence of any dissection and in absence of any in-stent thrombotic or plaque material (Figures $1 \mathrm{H}-\mathrm{J}$ ), and it showed fully preserved side-branch access (Figure $1 \mathrm{~K})$. Indeed, this stent has overall similar acute procedural results compared to other best-in-class stents [12-15], while optimal healing [16] and clinical outcomes of the device in all types of $\mathrm{PCl}$ including primary $\mathrm{PCl}$ in STEMI [13], are consistent with Alex Plus use as a modern workforce stent $[14,15]$. Alex Plus is a Cobalt-Chromium new generation coronary stent with an innovative coating for a consistent and controlled drug delivery. Bioresorbable polymer layers release sirolimus in a time-controlled process of slow biodegradation (lasting $\approx 8$ weeks), with optimal healing paired with an effective inhibition of neointima formation [16]. Favorable stent healing coverage occurs already at 1 month [16]. In addition, this stent type may have advantages in some specific indications such as the treatment of in-stent-restenosis [12].

Three days later the patient was discharged home in a good clinical condition. Prior to discharge, he received lifestyle modification education (inclusive of tobacco cessation patient-tailored personal plan) that is an important part of the NHF mission. NHF was founded in Bangladesh in 1978 at the initiative of National Professor Brig. (Rtd.) Abdul Malik to (i) promote cardiovascular health, educate and motivate people for prevention of cardiovascular diseases, (ii) provide in-hospital and out-patient services to patients suffering from cardiovascular diseases and associated conditions, (iii) train cardiovascular doctors, nurses, technicians and paramedics, and (iv) undertake and promote local high-quality research in cardiovascular diseases $[1,17]$. NHF is a member of the World Heart Federation and it plays a very active role in the Stent-For-Life [18] initiative in Bangladesh, fostering progress in cardiovascular prevention, medical staff and patient education, and introducing novel cardiovascular therapies in the country. Systematic NHF endeavors to improve the STEMI patients access to guideline-indicated therapy, including access to affordable state-of-the-art biodegradable-polymer thin-strut stent technology taken together with the routine operator training in a leading institution in the country, offer an important benefit to the individuals with cardiovascular disease and to the society in a fast-developing country.

\section{Acknowledgments}

We are grateful to Mr. Tomasz Badylak (MSc) and Mr. Paweł Kołacz (MSc) for their assistance in manuscript preparation.

\section{Conflict of interest}

The authors declare no conflict of interest. Operators were Prof. F. Malik, Dr TS. Huq and Prof. P. Musialek (NHF Annual Conference Invited Guest Operator).

\section{References}

1. Malik FT, Ishraquzzaman M, Kalimuddin M, et al. May Measurement Month (MMM) 2017: an analysis of blood pressure screening results in Bangladesh-South Asia. Eur Heart J Suppl 2019; 21 (Suppl D): D21-4.

2. Musialek P. Coronary thrombus management. In: Treatment Strategies - Interventional Cardiology. Cappato R, Eeckhout E, Evangelsta A, Stone GW (eds). Cambridge Research House, UK 2012.

3. Musiałek P, Pieniążek P. Tools to reduce periprocedural complications of embolism and myocardial infarction in percutanous coronary interventions [in Polish]. In: Kardiologia interwencyjna. Brzezińska-Rajszys G, Dąbrowski M, Rużyłło W, Witkowski A (eds.). PZWL, Warsaw 2009; 241-70.

4. Jolly SS, Cairns JA, Yusuf S, et al. Stroke in the TOTAL trial: a randomized trial of routine thrombectomy vs. percutaneous coronary intervention alone in ST elevation myocardial infarction. Eur Heart J 2015; 36: 2364-72.

5. Musialek P. TASTE-less endpoint of 30-day mortality (and some other issues with TASTE) in evaluating the effectiveness of thrombus aspiration in STEMI: not the "evidence" to change the current practice of routine consideration of manual thrombus extraction. Kardiol Pol 2014; 72: 479-87.

6. Zalewski J, Zmudka K, Musialek P, et al. Detection of microvascular injury by evaluating epicardial blood flow in early reperfusion following primary angioplasty. Int J Cardiol 2004; 96: 389-96.

7. Choudry FA, Weerackody RP, Jones DA, Mathur A. Thrombus embolisation: prevention is better than cure. Interv Cardiol 2019; 14: 95-101

8. Dąbrowski M, Tyczyński P, Bęćkowski $M$, et al. Is there still a place for thrombectomy? Adv Interv Cardiol 2016; 12: 68-9.

9. Wybraniec MT, Reichman-Warmusz E, Lelek M, et al. Aspiration thrombectomy and histopathologic examination of thrombus for early identification of embolic myocardial infarction. Adv Interv Cardiol 2019; 15: 489-91.

10. Tekieli L, Banaszkiewicz K, Moczulski Z, et al. Novel large-diameter manually-expandable stentriever, embolic prevention stent and flow reversal in large-thrombus-burden ICA proximal occlusion stroke. JACC Intv 2021 [Epub ahead of print]; doi: 10.1016/j. jcin.2021.07.050 
11. Roleder T, Jąkała J, Kałuża GL, et al. The basics of intravascular optical coherence tomography. Adv Interv Cardiol 2015; 11: 74-83.

12. Buszman PP, Michalak MJ, Pruski M, et al. Comparable vascular response of a new generation sirolimus eluting stents when compared to fluoropolymer everolimus eluting stents in the porcine coronary restenosis model. Cardiol J 2016; 23: 657-66.

13. Gąsior P, Gierlotka M, Szczurek-Katanski K, et al. Safety and efficacy of biodegradable polymer-coated thin strut sirolimus-eluting stent vs. durable polymer-coated everolimus-eluting stent in patients with acute myocardial infarction. Adv Interv Cardiol 2018; 14: 347-55.

14. Gasior P, Gierlotka M, Szczurek-Katanski K, et al. Bioresorbable polymer-coated thin strut sirolimus-eluting stent vs durable polymer-coated everolimus-eluting stent in daily clinical practice: propensity matched one-year results from interventional cardiology network registry. Catheter Cardiovasc Interv 2019; 93: E362-8.

15. Gasior P, Gierlotka M, Szczurek-Katanski K, et al. Biodegradable polymer-coated thin strut sirolimus-eluting stent versus durable polymer-coated everolimus-eluting stent in the diabetic population. Cardiol J 2021; 28: 235-43.

16. Dobrolińska M, Gąsior P, Roleder T, et al. Short-term healing response after implantation of the thin-strut, fast-releasing sirolimus-eluting biodegradable polymer-coated Alex Plus stent: optical coherence tomography study. Adv Interv Cardiol 2020; 16: 187-91.

17. Biswas AK, Haque T, Banik D, et al. Identification of significant coronary artery disease in patients with non-ST segment elevation acute coronary syndrome by myocardial strain analyses using three dimensional speckle tracking echocardiography. Echocardiography 2018; 35: 1988-96.

18. Wein B, Bashkireva A, Au-Yeung A, et al. Systematic investment in the delivery of guideline-coherent therapy reduces mortality and overall costs in patients with ST-elevation myocardial infarction: results from the Stent for Life economic model for Romania, Portugal, Basque Country and Kemerovo region. Eur Heart J Acute Cardiovasc Care 2020; 9: 902-10. 